\title{
The Program of Formation of Emotional Stability of Personnel in the Hospitality Industry
}

\author{
Ekaterina Vezetiu*, Ekaterina Vovk, Natalia Gorbunova, Lyudmila Bura and Yana \\ Zalevskaya
}

V.I. Vernadsky Crimean Federal University, 295007, Prospekt Vernadskogo, 4, Simferopol, Russia

*Corresponding author.Email: nauchnyyotdel@mail.ru

\begin{abstract}
The topic of emotional stability forms a topical theoretical and practical problem. It becomes the subject of the study of psychophysiology, pedagogy, philosophy and social sciences, both domestic and world experts are engaged in it, therefore, the problem can be considered interdisciplinary. Special attention is paid to the emotional stability of the personnel of the enterprises of the hospitality industry as a polysystemic property of character, which is characterized by emotional balance. The purpose of this study is to study the emergence of emotional stability among workers in the hospitality industry. In order to carry out the work, both general scientific and psychological methods were used. Among the theoretical ones - the study of references on this topic, collection of abstracts, classification of information. Empirical methods include observation, talking, filling out questionnaires, putting down expert assessments and conducting tests. Using the SPSS 13.0 program on the Windows operating system, it was possible to conduct a comparative, quantitative and qualitative analysis. The latter were used to collect relevant information about the level of emotional stability and connection with other personality traits. The effectiveness of the applied program was also confirmed by exploiting the unique author's program for assessing the emotional stability. Using the program, the subject will be able to block those factors that reduce stability and reinforce it with appropriate conditions.
\end{abstract}

Keywords: emotional stability, personnel of enterprises in the hospitality industry, formation.

\section{INTRODUCTION}

The first experimental studies of emotional stability were carried out in the 19th century, when this phenomenon was studied within the framework of Charles Darwin's "rudimentary" theory and JamesLange's "peripheral" theory. It was found that emotional stability appeared in humans in the process of evolution, its origins must be sought in physiological manifestations and adaptive mechanisms [1].

In the papers of a number of researchers, emotional stability, one way or another, is associated with the phenomenon of emotional intelligence, understood as intelligence in the emotional regulation of behavior, the most important determinant of the success of life [2], emotional self-control [3], emotional maturity of the individual [4].

I.F. Arshava notes that there are various forms of displaying the assessment of a person's emotional stability by parameters: the level of formation of emotional intelligence; the predominance of emotional stability resources in the individual experience, development of an active strategy to overcome the concentration on the problem; features of the manifestation of higher mental functions (communicative, sense of humor); presence or absence of psychosomatic disorders [2].

In the papers of T.A. Pashko, emotional stability is associated with the phenomenon of emotional selfcontrol and is defined as the ability of a person to control, identify and, if necessary, correct their own emotional manifestations, which helps to stimulate selfimprovement and increase the effectiveness of activities. The model of emotional self-control, as defined by the scientist, consists of two components: structure and mechanism. The structure includes a motivational-value component, a self-assessment unit, a reflexive component, a volitional component, and an intellectual 
unit. The mechanism includes control and correction. Psychological determinants of emotional self-control are: personal reflection, emotional intelligence, volitional qualities, motivation for achievement and self-esteem [4].

I.G. Pavlova considers emotional stability as an element of emotional maturity, which, in turn, is interpreted by the author as "an integrative personality quality that characterizes the degree of development of the emotional sphere at the level of adequacy of emotional response in certain socio-cultural conditions" [5]. To the important signs of an emotionally mature personality I.G. Pavlova attributes the following: adequacy in the perception, assessment and understanding of one's own emotions and the emotions of others, arbitrariness in managing one's emotions, use of emotional expression as a means of communication. Emotional maturity is a phenomenon of an emotional order, it acts as the ability to adequately react emotionally in specific social conditions, and, therefore, has emotional stability.

A number of authors consider emotional stability as a factor ensuring the stability of the individual as a whole. Therefore, E. Erickson interprets emotional stability as a factor in formation and maintenance of the integrity of the personality. Wherein, the author focuses on the fact that "the integrity of the personality that is formed at a certain age stage is ensured not only by intellectual and physical skill, but also by the stability, cohesion, independence of the moral views and assessments developed by the adolescent, that is, by a stable worldview" [6, p. 243].

Based on the purpose of the study, psychological studies are of particular interest. Their authors pay attention to the structure of emotional stability, and also highlight the criteria for its formation.

K.V. Pilipenko considers emotional stability as "a complex dynamic integrative personality trait that ensures high productivity of activity and behavior in difficult emotionally stressful conditions". The structure of emotional stability, in her opinion, is represented by: psychophysiological, emotional-volitional, cognitivereflexive, adaptive and social-perceptual substructures. Therefore, integration, compatibility and representation of these substructures gives stability or instability to development of emotional stability. For formation of stable emotional stability, it is necessary to activate its substructures, the basis of which shall be the formed skills of reflection, self-knowledge, adaptability, meditation, self-regulation, self-control and etc. [7].

In the context of our paper, the study of M.Yu. Buslaeva is of great interest. This author defines the concept of "emotional stability" as the readiness to solve constructively emotive situations in the process of professional activity. The structure of emotional stability is represented by the following components: emotional (balance-imbalance between the personality and the social environment, the level of personal anxiety, neurotization, typical emotional reactions, and etc.); motivational (self-organization, self-regulation, self-government of a person in a tense situation based on his/her system of motives); strong-willed (initiation of actions, control of behavior, and etc.); cognitive (evaluating the information received, predicting events, making decisions in stressful situations) [8].

Analysis of the references on the problem we are studying has shown that emotional stability is a functional, harmonizing system of emotional regulation of activity, the ability to maintain certain emotional states. It acts as one of the psychological factors of reliability, efficiency and success of actions in an environment of increased mental tension. In our study, this theoretical position is the starting point for the subsequent empirical study of the phenomenon of emotional stability.

\section{MATERIALS AND METHODS}

The empirical part of this paper is based on the hypothesis of the study that formation of emotional stability in personnel of enterprises in the hospitality industry occurs under the condition of: using a specially developed, theoretically grounded and empirically effective training program aimed at: 1) direct training in emotional stability; 2) indirect formation of emotional stability through development of psychological factors that increase emotional stability, and blocking factors that reduce its level.

The purpose of the study is to study the features of formation of emotional stability in driving school students.

In accordance with the purpose of the study, the following tasks were solved:

1. Analysis of the theoretical and methodological problem of emotional stability of personnel of enterprises in the hospitality industry, study of the structure and features of formation.

2. Development and testing of a training program for formation of emotional stability of personnel in the hospitality industry.

The psychodiagnostic complex includes study methods: the severity of the components of emotional stability (modified method of T. Dembo - S. Rubinstein "Placing oneself on the scale of emotional stability"), factors of emotional stability - the degree of emotional stability, neurotization (the method of L.I. Wasserman), the degree of stress resistance and social adaptation ( $T$. Holmes and Rage), the type of emotional reaction to the effects of environmental stimuli (the method of V.V. Boyko); a wide range of personal qualities (16-factor 
questionnaire by R. Cattell); indicators of social adaptability ("Test questionnaire of social adaptability" by O.P. Sannikova, O.V. Kuznetsova); difficulties faced by hospitality industry workers (Emotional Resilience Questionnaire).

In total, 86 employees of hospitality industry enterprises (Yalta, Republic of Crimea, Russia) rook part in the study. The contingent of the subjects consisted of students aged 18 to 56 years (67\% women and $33 \%$ men).

\section{RESULTS AND DISCUSSION}

When arranging the work on formation of emotional stability, we relied, first of all, on the fact that one of the main forms of group developmental work used in modern psychology is training.

Modern psychology offers a wide variety of different technologies for conducting the training work. Within the formative stage of our experiment, active group methods allowing them to master the necessary skills and abilities to overcome stressful situations were used to work with the personnel of enterprises in the hospitality industry. The combination of these methods is one of the most affordable ways to significantly accelerate group learning, which is achieved through intense emotional reinforcement and increased feedback from participants.

Based on the goal of the training, which was to form the emotional stability of the personnel of the hospitality industry, its working definition was formulated. Emotional stability training for personnel of hospitality industry enterprises is a form of work aimed at using methods of an interactive, autoactive, psycho-preventive and psycho-correctional type. The goal is to reinforce external as well as internal sources of emotional stability of the individual.

In the course of the training developed and conducted by us, conditions were created for psychological correction and development of emotional stability of the personnel of the enterprises of the hospitality industry. WIthin the training, individual and group reflections of reality were compared, the components were comprehended, an understanding of those factors that influence behavior in specific circumstances was developed. To understand the body's response, stress factors and personality responses were studied. Within the lesson, special attention was paid to reducing emotional stress, searching for resources within the personality that help control the emotional state. The participants of the training developed the skills of controlling emotions, learned to expand the formats of behavior in stressful circumstances. The training was structured in such a way that each of the participants could develop an individual coping strategy for behavior in stressful situations, learn to overcome stress.

To conduct training sessions with the personnel of enterprises in the hospitality industry, a specially organized room was used, in which circular classroom work was provided, classes of a motor format were conducted, and the opportunity to retire was implemented. Depending on the specific conditions, the number of sessions, their content, the sequence of performance, and duration of the exercises varied.

The training was designed for the personnel of enterprises in the hospitality industry and assumed the presence of a certain level of reflection of its participants. The content of the training was implemented within 28 academic hours $(+17$ hours of independent work on the instructions of the training leader). This work was carried out in a group of 15 people, classes (4 academic hours each) were held regularly for 7 days. Each unit of the training involved a separate lesson or a series of lessons. Each lesson began with a greeting from the facilitator, followed by an activator exercise.

The training program included an alternation of theoretical (mini-lectures) and practical material. The end of the lesson was accompanied by a reflection of its content, an assessment of the emotional state of the participants, as well as the text of farewell chosen by the group in the first lesson. The training program included four units: diagnostic (implemented twice), theoretical (informational), instrumental and psychotechnics unit.

A summary of the training program:

\section{Lesson No. 1}

Acquaintance. The coach gets to know the participants of the training, introduces the topic of the meeting, determines the format of the training. Then, during the "Waiting", the potential results that the participants of the exercises want to achieve are collected. Then they collectively draw up rules that determine further work in formation of a stable emotional background. We shall note the individuality of the rules, which allows both the drafting of general provisions and wording the individual group provisions. To consolidate the instructions, the lesson "Incomplete sentences" is conducted, during which the group is convinced of the clarity of the adopted rules. Acquaintance of the participants is carried out in the format of the "Presentation" game.

Conducting the exercise "Associative series" allows to form an understanding of the nature of stress and the situations in which they appear. Through this lesson, it is possible get into the topic of the training.

In order to help the subjects to realize and verbally express their own feeling of stress, as well as to deal with emerging emotions, to determine the personal 
attitude, to identify urgent problems, to make sure of their emotional resources that help in the fight against negatively colored emotional situations, the exercise "I, emotions and stress" is used.

After that, "Stress" lecture in the mini-format is held. Using brainstorming, the training participants define the very concept of stress, and then, using this definition, listen to the understanding of stress from the point of view of various psychological practices. The presented historical background allows to look at the phenomenon of stress through the eyes of prominent researchers. This is followed by a self-assessment of the concepts and definitions that are most applicable in the context of this lesson.

A separate emphasis is put on the destructive consequences of regular experiences. Among others, there are declines in productivity, statistical increases in physical problems, difficulties in socialization, deterioration in professional skills, and a decline in emotional stability. By analyzing the sources of stress, the coach must show that moderate experiences are a completely natural and even, in some sense, a beneficial reaction of the body, allowing solve problems to more effectively. To be convinced of this statement, a lecture "The Pros and Cons of Stress" is held, during which the participants understand what a productive impulse the experience of stress can be.

Reinforcing the passed, the coach begins the exercise "Cure for Stress", during the latter the above is summarized, and the participants share the knowledge gained. An additional effect is provided by the exercise "Ritual of the Mood for Success", which forms and motivates the desire to complete all the training tasks. To consolidate the information received and the skills acquired, it is necessary to perform an independent mobilizing micro-pause, the passage of which requires about 5 minutes daily. Afternoon or evening classes are preferred.

\section{Lesson No. 2}

Group rules. All members of the group are invited to assess the degree of their own anxiety at the start of the training using a 10 -point system (0 points - no anxiety, 10 points - maximum anxiety). The rules of the group's work are specified, discussed, and, if necessary, changed. Participants of the training can either agree with the presented rules, or jointly adjust and offer new canons of the lesson. The coach shall undertake to monitor the fulfillment of the accepted conditions.

The exercise "I am like this today ..." charges with an emotional mood, develops the ability to analyze emotions, to talk about the latter.

By playing the "Build by Growth" game, it turns out to reveal the influence of the consequences of frustration on the final model of behavior. Frustration factors include obvious social needs, including avoiding the use of sight to explore the world, and minimizing communication.

The exercise "Resource of Emotional Stability" was created to determine the resources of an individual as a phenomenon with the subsequent classification of the collected information. The coach explains why it is important to strengthen and maintain own emotional reserves in every possible way.

Further, the training participants are offered an algorithm of actions that help to cope with negative emotions, reduce emotional stress (exercise "I am Angry when ...").

"Coping Strategies and their Role in Overcoming Emotional Instability" is an exercise that helps to form an understanding of "coping", determine its relevance and learn about the main methods of coping with unstable states developed by R. Lazarus and S. Folkman. The lesson discusses the difference between active and passive suppression of emotional instability, determines the conditions in which certain techniques are applicable. Participants conclude with personal examples of factors that can help relieve stress.

To overcome emotionally unstable states (reducing the action of intrapersonal stress factors), the exercise "Image of the I" is used (according to M. James, D. Jongward).

In order to consolidate the acquired knowledge and skills, it is offered to complete a number of tasks for independent work:

1. At the sight of your reflection, say "I'm great, I'm fine" every day for one week. The goal of the method is to create the desired feeling of calmness.

2. Focus on the moments of self-deprecation, after a two-day recording of each fact, try to suppress each highlighted combination of circumstances.

3. To add the "golden labels" included in a separate list at this training.

Participants in the training shall learn that a person who has achieved sufficient self-confidence does not need "labels", nor does he/she need feelings, usually negative, that "collect" the child's ego-state, ideas about oneself imposed from the outside, even if they are "gold".

\section{Lesson No. 3}

The rules of the group are specified, discussed, and, if necessary, changed. Participants of the training can either agree with the presented rules, or jointly adjust and offer new canons of the lesson. The coach shall undertake to monitor the fulfillment of the accepted conditions. 
"Elbows" developed by K. Fopel, help to establish contact, deduce stereotypical patterns of greeting, develop creative thinking and empathy.

To familiarize the participants with the types of stressful situations in professional activity, a minilecture "Stressful Situations in Professional Activity" is used. The coach talks about the fact that currently there is no coherent classification of those situations in which stress occurs. Instead of a single list, the Lazarus classification built on three types of difficult circumstances: "loss", "threat of loss" and "challenge" are presented. "Loss" refers to the loss of time, material or intangible value. "Challenge" — a situation that requires an exorbitant effort.

Participants provide examples of stressful circumstances at work, composing their own gradation.

Lesson "Two by two, or the new Julius Caesar", created by Kipnis, instills the correct behavior in stressful situations, develops the ability to maintain attention and concentrate under the pressure of environmental factors. The subsequent "Tempo" game restores emotional resources, allows to more confidently perform the next game, helps to accumulate strength for formation of a more objective image of stressful situations. "Good and Bad" game.

This is followed by a short lecture "The Stress Management Model by J. Greenberg. Positive thinking". The specialist emphasizes the existence of clear rules for managing negative emotions, increasing individual emotional tolerance. The essence of the practice is an integrated approach, ideally suited to the training format. Note that the model works only with the support of thinking in a positive way, which allows to assess stressful circumstances calmly and sensibly. Creativity also increases, the disclosure of previously unobvious psychological potential begins.

The group gets acquainted with the results of the comparison of optimists and pessimists conducted by M. Zeligman. Under the guidance of the coach, the concept of positive thinking, a positive outlook on reality is discussed. The characterization of the optimist is given, with a remark on presentation of stress as natural life situations that need a calm, sound assessment.

"Resilience" element demonstrates the resources for enhancing the self-esteem of participants.

Since any unit assumes a reinforcing task in the form of independent work, we offered to familiarize ourselves independently with and master the method of affirmation, i.e. finding words, self-hypnosis formulas that help a person tune his/her mind to a positive wave.

\section{Lesson No. 4}

Group rules. See Lesson No. 3.
The game "Tanya sits here ..." is aimed at eliminating worries and tensions, getting to know the training participants better, as well as defining a strategy of actions in certain circumstances. Participants learn to react quickly to a situation, make quick decisions and confidently work with external factors.

The additional lecture "Prelaunch Excitement" introduces the concept contained in the title of the exercise. The audience then listens to a series of practices to effectively deal with the experience before and during public speaking. The coach notes that a detailed description of the presented methods will take place during the sixth lesson of the training.

In order to develop confidence in disturbing circumstances, to overcome the fear of the future, the exercise Andreas "Circle of Perfection" is used.

A short lecture "Emotional Burnout Syndrome" includes an acquaintance with the terminology presented by K. Maslach, highlighting the factors influencing the development of emotional burnout. The types of the syndrome, methods of its prevention are also considered. Participants give examples of situations in which the syndrome occurs.

In order to generalize the theory obtained, to begin an active exchange of experience, the group proceeds to the "Vaccination against Burnout".

The next lecture "Rules for Transmission and Acceptance of Criticism" informs about the difference between constructive and destructive criticism, about the methods of disseminating negative information. Lecture is interchangeable with group discussion about the positive and negative aspects of criticism.

"Decent Response" exercise helps to work out the correct resolution of conflict situations.

The task for consolidating the received material is an exercise for independent work "Fixing a Point".

\section{Lesson No. 5}

Group rules. See Lesson No. 3.

"Positive Monologue" Exercise (Authors A. Ellis, and K. McLaren) is aimed at accepting your "I" in a positive way; development of reflection.

The "Time Management" lecture begins with a presentation of time as an irreplaceable, but regulated resource, as well as a description of the individual's inability to control time as a result of individual incompetence, the specifics of interpersonal interaction; organizational and structural problems, and etc.".

The emphasis is on the difficulties of time management, internal and external obstacles to its optimal use. 
To analyze the orientation in free time, the "Minute" session begins, as well as "Business time - fun hour", which allows to develop a personal strategy for controlling time.

This is followed by "Time - Management according to Gleb Arkhangelsky" mini-lecture. The lecture takes place in two stages:

I-st stage: "Elimination of Small Unpleasant Affairs".

II-nd stage: "Deglobalization" of major tasks.

In order to form the skills of rational time management, "Elephants and Frogs" exercise (time management, G. Arkhangelsky) is used.

In order to consolidate the knowledge gained, it is offered to complete an assignment for independent work: master the technique of liberation from a destructive feeling of resentment, according to L.A. Pergamenshchik.

\section{Lesson No. 6}

Group rules. See Lesson No. 3.

To "warm up" the group and have a positive attitude towards further work, it is offered to perform the "Lotto" exercise.

When conducting "Methods of Self-Regulation", the lecturer introduces the group to the basic terminology, talks about the importance of self-discipline and the importance of a competent reaction in stressful circumstances. Participants share individual techniques in this direction.

"Relaxation" exercise is aimed at mastering the methods of self-hypnosis and mastering various relaxation techniques. After completing this exercise, the group closes their eyes and performs the "Float", and then "Rest", allowing to rest properly and learn the right relaxation.

The next stage is "Posture" lecture, during which the importance of the correct position of the spine during energy metabolism within the body is explained. It is also reminded that posture is often an indicator of emotional stability for others.

Strengthening takes place in the "Wall" exercise, which helps to ensure the importance of posture, eliminate muscle clamps and other back problems.

The assignment for independent work involves mastering the technique of forming a positive emotional background of life.

\section{Lesson No. 7}

Group rules. See Lesson No. 3.

In order to develop the ability to understand others, to form a positive attitude towards the future and to work together, the group members use the "I am among you" technique.

"Let's talk about Yesterday" exercise serves as a reflection of previous lessons; control over homework.

Performing "Breathing is the Basis of all Relaxation Methods" lecture, the lecturer tells how strong the connection between breathing and the emotional state of a person is. Experiencing stress, a person begins to breathe faster, thereby straining the lungs and heart. The group learns that it is enough to learn how to breathe in order to be in complete control of their experiences.

Exercises are preceded by acquaintance with the basic provisions of pranayama, known as a set of practices for curbing energy, promoting the adaptive functions of the body by "debugging" the respiratory processes.

The coach talks about the types of breathing practiced on the subsequent elements.

The first method, "Breath Control", allows to feel the aforementioned connection between breathing and emotional state. Here, the group learns to breathe correctly in order to calm down as soon as possible.

Using "Meditation" lesson, in which the coach informs about the latest studies proving the benefits of meditation for a person, the group shares their opinion and discusses the theory they have received. After that, participants of the training will learn about various meditation practices, consolidating the information on "Meditation". The group trains attention, concentration on emotions, the ability to abstract.

"Visualization as a Method of Self-Regulation" lecture begins with the actual importance of the visualization method, its influence on the improvement of imagination and fantasy.

"The Frigate on which I am Sailing" element allows to define and consolidate the emotional states of the participants in the exercises, as well as form a clear plan to overcome stress

In order to control the assimilation of the information received at the training sessions, the participants are offered to perform "Portrait of an Emotionally Stable Person" exercise.

"Group Map" Exercise (K. Fopel) is devoted to generalization of the information obtained during the training sessions, the orientation of the participants to use the acquired knowledge and skills, the analysis of fulfillment of their expectations from the training, and etc.

Judging by the results of using the program, one can judge its effectiveness, which allows to act as a significant tool in theoretical and practical study. To confirm the statistical efficiency, a comparison of the 
results of psychological diagnostics before and after classes was made. Data are expressed in the 4th table.

Table 1. Comparison of the indicators of the control and experimental groups on the diagnostic section (average indicators in points) according to the Student's tcriterion

\begin{tabular}{|c|c|c|c|c|}
\hline \multicolumn{3}{|c|}{ Emotional Resilience } & Control & Experimental \\
\hline \multirow{3}{*}{$\begin{array}{l}\text { V.V. Boyko (a } \\
\text { type of emotional } \\
\text { response to } \\
\text { environmental } \\
\text { stimuli) }\end{array}$} & \multicolumn{2}{|l|}{ Euphoric } & 20.02 & 20.71 \\
\hline & \multicolumn{2}{|c|}{ Refractory } & 13.1 & 13.17 \\
\hline & \multicolumn{2}{|l|}{ Dysphoric } & 4.83 & 4.79 \\
\hline \multicolumn{3}{|c|}{$\begin{array}{l}\text { The technique of L.I. Wasserman } \\
\text { (level of neurotization) }\end{array}$} & 17.43 & 17.14 \\
\hline \multirow{2}{*}{$\begin{array}{l}\text { The technique of } \\
\text { T.D. Dubovitskaya } \\
\text { and A.V. Krylova } \\
\text { to identify } \\
\text { adaptability }\end{array}$} & $\begin{array}{l}\text { to the } \\
\text { group }\end{array}$ & 1 & 9.4 & 9.4 \\
\hline & $\begin{array}{l}\text { to } \\
\text { activity }\end{array}$ & 2 & 9.8 & 11.1 \\
\hline $\begin{array}{l}\text { The technique of } \\
\text { T. Holmes and } \\
\text { R. Rage on } \\
\text { determination of } \\
\text { stress resistance } \\
\text { and social } \\
\text { adaptation (stress } \\
\text { resistance) }\end{array}$ & \multicolumn{2}{|c|}{$\begin{array}{l}\text { Resistance } \\
\text { to stress }\end{array}$} & 154 & 149 \\
\hline
\end{tabular}

Table 2. Comparison of the indicators of the control group on the diagnostic and control section (average indicators in points) according to the Student's t-test

\begin{tabular}{|l|l|c|c|}
\hline \multicolumn{2}{|l|}{ Emotional Resilience } & Diagnostic & Control \\
\hline $\begin{array}{l}\text { The technique of } \\
\text { V.V. Boyko (type of } \\
\text { emotional response to } \\
\text { environmental } \\
\text { stimuli) }\end{array}$ & Euphoric & 20.02 & 20.36 \\
\cline { 2 - 4 } & Refractory & 13.1 & 13.64 \\
\cline { 2 - 4 } & Dysphoric & 4.83 & 4.88 \\
\hline $\begin{array}{l}\text { The technique of L.I. Wasserman } \\
\text { level of neurotization) }\end{array}$ & 17.43 & 17.67 \\
\hline $\begin{array}{l}\text { The technique of } \\
\text { T.D. Dubovitskaya } \\
\text { and A.V. Krylova to } \\
\text { identify adaptability }\end{array}$ & $\begin{array}{l}\text { TO } \\
\text { THE } \\
\text { group }\end{array}$ & $\begin{array}{l}\text { TO the } \\
\text { activity }\end{array}$ & 2 \\
\hline $\begin{array}{l}\text { The technique of T. } \\
\text { Holmes and R. Rage } \\
\text { on determination of } \\
\text { stress resistance and } \\
\text { social adaptation } \\
\text { (stress resistance) }\end{array}$ & $\begin{array}{l}\text { Resistance } \\
\text { to stress }\end{array}$ & 9.4 & 9.6 \\
\hline
\end{tabular}

Therefore, the training showed positive changes in the level of stress resistance among the personnel of the hospitality industry. Neurotization became lower, adaptability increased, the types of emotional responses to certain stressful circumstances changed positively. The personal factors deduced by R. Ketell also changed. Namely, there was a decrease in affectolimia, a tendency to feel guilty, and tension. On the contrary, dominance, courage, self-sufficiency and the level of self-control have grown.
For maximum objectivity in the study of emotional stability, the application of the described methods is required at other stages of professional formation, personality development.

Table 3. Comparison of the indicators of the experimental group before and after the training (average indicators in points) according to the Student's t-criterion

\begin{tabular}{|c|c|c|c|c|}
\hline \multicolumn{3}{|l|}{ Emotional Resilience } & $\begin{array}{l}\text { Before } \\
\text { the }\end{array}$ & $\begin{array}{l}\text { After } \\
\text { the }\end{array}$ \\
\hline \multirow{3}{*}{$\begin{array}{l}\text { The technique of V.V. } \\
\text { Boyko (a type of } \\
\text { emotional response to } \\
\text { environmental stimuli) }\end{array}$} & \multicolumn{2}{|l|}{ Euphoric } & $20.71^{*}$ & 17.4 \\
\hline & \multicolumn{2}{|c|}{ Refractory } & 13.17 & $15.52 *$ \\
\hline & \multicolumn{2}{|c|}{ Dysphoric } & 4.79 & 3.76 \\
\hline \multicolumn{3}{|c|}{$\begin{array}{l}\text { The technique of L.I. Wasserman } \\
\text { (level of neurotization) }\end{array}$} & 17.14 & $13.55^{*}$ \\
\hline \multirow{2}{*}{$\begin{array}{l}\text { The technique of } \\
\text { T.D. Dubovitskaya and } \\
\text { A.V. Krylova to } \\
\text { identify adaptability }\end{array}$} & $\begin{array}{l}\text { TO } \\
\text { THE } \\
\text { group }\end{array}$ & 1 & $9.4^{*}$ & 12.0 \\
\hline & $\begin{array}{l}\text { TO the } \\
\text { activity }\end{array}$ & 2 & 11.1 & 12.3 \\
\hline $\begin{array}{l}\text { The technique of T. } \\
\text { Holmes and R. Rage on } \\
\text { determination of stress } \\
\text { resistance and social } \\
\text { adaptation (stress } \\
\text { resistance) }\end{array}$ & \multicolumn{2}{|c|}{$\begin{array}{l}\text { Resistance } \\
\text { to stress }\end{array}$} & $145 * *$ & 125 \\
\hline
\end{tabular}

Table 4. Comparison of the indicators of the control and experimental groups on the control section (average indicators in points) according to the Student's tcriterion

\begin{tabular}{|c|c|c|c|c|}
\hline \multicolumn{3}{|c|}{ Indicators of emotional stability } & Control & Experimental \\
\hline \multirow{3}{*}{$\begin{array}{l}\text { The technique of } \\
\text { V.V. Boyko (a } \\
\text { type of emotional } \\
\text { response to } \\
\text { environmental } \\
\text { stimuli) }\end{array}$} & \multicolumn{2}{|l|}{ Euphoric } & 20.36 & 17.4 \\
\hline & \multicolumn{2}{|c|}{ Refractory } & 13.64 & $15.52 *$ \\
\hline & \multicolumn{2}{|c|}{ Dysphoric } & 4.88 & 3.76 \\
\hline \multicolumn{3}{|c|}{$\begin{array}{l}\text { The technique of L.I. Wasserman } \\
\text { (level of neurotization) }\end{array}$} & $17.67^{*}$ & 13.55 \\
\hline \multirow[t]{2}{*}{$\begin{array}{l}\text { The technique of } \\
\text { T.D. Dubovitskaya } \\
\text { and A.V. Krylovoy } \\
\text { (adaptation): }\end{array}$} & $\begin{array}{l}\text { TO } \\
\text { THE } \\
\text { group }\end{array}$ & 1 & 9.6 & $12.0 *$ \\
\hline & $\begin{array}{l}\text { TO the } \\
\text { activity }\end{array}$ & 2 & 10.1 & 10.3 \\
\hline $\begin{array}{l}\text { The technique of } \\
\text { T. Holmes and } \\
\text { R. Rage on } \\
\text { determination of } \\
\text { stress resistance } \\
\text { and social } \\
\text { adaptation (stress } \\
\text { resistance) }\end{array}$ & \multicolumn{2}{|c|}{$\begin{array}{l}\text { Resistance } \\
\text { to stress }\end{array}$} & 149 & $125^{*}$ \\
\hline
\end{tabular}

\section{CONCLUSION}

The analysis of the level of stability of the personality before emotional experiences was based on 
the theory of emotional phenomena, as well as the theory of self-regulation. Additionally, a systematic approach combined with the concept of integrity, professional activity, interaction and development was used. The stability of the emotional system is assessed as a factor of mental formation, an integrative systemic property of a person, characterized by a balance of emotions, productivity of learning.

This paper made it possible to establish the insufficient development of emotional stability among the subjects. In practice, it became clear that the properties accompanying stress negatively affect emotional stability. Social adaptability, self-sufficiency, self-confidence, strength of personality and courage in a social environment have the opposite effect.

The result was development of the author's training to strengthen the emotional stability of personnel in the hospitality industry. The resulting technique is focused on integral emotional stability and its individual manifestations, that is, on personality characteristics. We also succeeded in eliminating those factors that stop the normalization of emotional stability.

Correlation and qualitative analysis of the results of the experimental work confirmed the effectiveness and appropriateness of use of training work for formation of emotional stability of personnel of enterprises in the hospitality industry.

\section{REFERENCES}

[1] Yu. N. Kuliutkin. Personal factors in development of students' cognitive activity in the learning process. Issues of Psychology, 5 (1984) pp. 41-44.

[2] I. F. Arshava. Human Emotional Stability and its Diagnosis. Institute of Psychology. G.S. Kostyuk, 2007, pp. 33.

[3] E. L. Nosenko. Emotional Intelligence. Higher School. 2003, pp. 126.

[4] T. A. Pashko. On the Problem of the Formation of Psycho-Emotional Self-Regulation Skills in the process of Teaching Young Drivers Of Vehicles. Fundamental and Applied Problems of Pedagogy and Psychology in the Educational and Social Context. Materials of the international conference, Moscow State Pedagogical University, Moscow, 2020, pp. 164-169.

[5] O. I. Pavlyuk. Psychological Support of the Process of Training Future Drivers: a Pilot Study. Pravo. Economy. Psychology, 2 (2015) pp. 52-57.

[6] E. Erickson, Identity: Youth and Crisis; [translation from English/Пeneral editorship and foreword. A.V. Tolstykh], Moscow, Progress, 1996, pp. 344.
[7] I. V. Okhremenko. Psychology and pedagogy of higher education: a textbook for undergraduate and graduate programs, Moscow, Yurayt Publishing House, 2017, pp. 178.

[8] M. Yu. Buslaeva. Psychological and Pedagogical Conditions for Formation of Emotional Stability of Students of a Pedagogical College: dis. of Cand. of Psychol. Sciences: 19.00.07, Cherkassy, 2009, pp. 196. 